\title{
Association between Metabolic Syndrome and Microalbuminuria in Korean Adults
}

\author{
Hyun-Ok Lee, Hyun-Ju Bak, Jin-Young Shin, Yun-Mi Song*
}

Department of Family Medicine, Samsung Medical Center, Sungkyunkwan University School of Medicine, Seoul, Korea

\section{ABSTRACT}

Background: We conducted a population-based cross-sectional study of Korean adults to evaluate the association between metabolic syndrome and microalbuminuria as a marker for early-stage chronic kidney disease.

Methods: A total of 8,497 adults (3,625 men and 4,872 women) who participated in the Korea National Health and Nutrition Examination Survey between 2011 and 2012 were included. Metabolic syndrome was defined according to recommendation from a joint interim statement of international organizations published in 2009. Microalbuminuria was defined as a urinary albumin-to-creatinine ratio of 30 to $300 \mathrm{mg} / \mathrm{g}$. The association between metabolic syndrome and microalbuminuria was evaluated using logistic regression analysis with adjustment for covariates while considering sampling weights and the complex survey design.

Results: The prevalence of microalbuminuriain subjects with metabolic syndrome was $11 \%$ for men and $14.4 \%$ for women, whereas the prevalence in subjects without metabolic syndrome was $3.1 \%$ for men and $6.7 \%$ for women. Metabolic syndrome was significantly associated with an increased risk of microalbuminuriain both women (odds ratio, 2.79; 95\% confidence interval, 2.01 to 3.88) and men (odds ratio, 3.00; 95\% confidence interval, 2.11 to 4.27). All components of the metabolic syndrome were associated with a significantly increased risk of microalbuminuria with the strongest association for high blood pressure. The risk of microalbuminuria increased in a dose-dependent manner (P-value for trend $<$ 0.001 ) with the number of metabolic syndrome components observed for both sexes.

Conclusion: These findings suggest that metabolic syndrome is a risk factor for chronic kidney disease from an early stage.

Keywords: Metabolic Syndrome; Albuminuria; Hypertension; Obesity; Dyslipidemias

Received: August 19, 2014, Accepted: February 25, 2015

*Corresponding Author: Yun-Mi Song

Tel: +82-2-3410-2442, Fax: +82-2-3410-0388, E-mail: yunmisong@skku.edu

Korean Journal of Family Medicine

Copyright (C) 2015 The Korean Academy of Family Medicine

This is an open-access article distributed under the terms of the Creative Commons Attribution Non-Commercial License (http://creativecommons.org/licenses/by-nc/3.0) which permits unrestricted noncommercial use, distribution, and reproduction in any medium, provided the original work is properly cited. 


\section{INTRODUCTION}

Metabolic syndrome (MetS) comprises a cluster of metabolic abnormalities associated with insulin resistance. With the increase in the proportion of the population with obesity and a sedentary lifestyle in recent decades, MetS prevalence has been increasing worldwide. ${ }^{1)}$ The prevalence of MetS among adults in the United States has increased steadily since 1988. ${ }^{2}$ According to the Korean National Health and Nutrition Examination Survey (KNHANES), the age-adjusted MetS prevalence in Korea increased from $24.9 \%$ in 1998 to $31.3 \%$ in 2007. ${ }^{3)}$

MetS is a well-known risk factor for diabetes and cardiovascular disease. ${ }^{4,5)}$ In addition, an association between MetS and renal disease has been suggested, ${ }^{6,7)}$ and several studies ${ }^{6,89}$ have found a significant association between MetS and a decrease in the estimated glomerular filtration rate (GFR), which is indicative of advanced chronic kidney disease (CKD). Given that the number of patients on dialysis therapy probably related to end-stage renal disease has been increasing in Korea, ${ }^{10)}$ it seems necessary to identify risk factors for renal disease at an early, modifiable stage.

Microalbuminuria is defined by an abnormally high albumin excretion rate in the urine (30 to 300 $\mathrm{mg} / \mathrm{g}$ creatinine) and has been used to identify individuals at increased risk of cardiovascular disease and CKD as it reflects vascular endothelial damage at an early stage of these diseases, whereas GFR is generally well preserved until later stages of CKD. ${ }^{11)}$

To date, only a few studies, including one Korean study, ${ }^{12-15)}$ have evaluated the association between MetS and microalbuminuria as a marker for early-stage CKD. In addition, findings regarding the relationship between individual MetS components and microalbuminuria were inconsistent between these studies. For example, high density lipoprotein cholesterol (HDLC) and triglyceride levels were not associated with microalbuminuria in some studies ${ }^{13,15)}$ but were significantly associated with microalbuminuria in the Korean study. ${ }^{12)}$ Furthermore, the analysis of covariates was limited, and the effects of alcohol consumption and physical activity were not considered. ${ }^{12,13,15)}$

Thus, in this study, we evaluated the association between MetS and microalbuminuria using the large volume of population-based data available from the KNHANES and considering a range of covariates.

\section{METHODS}

\section{Study Subjects}

This study is a secondary analysis of data from the KNHANES, which is a cross-sectional study conducted by the Korea Centers for Disease Control and Prevention using nationally representative samples selected using a stratified, multistage, probability-sampling design on the basis of sex, age, and geographical area of the registered households. ${ }^{16)}$

Our study subjects were Korean adults aged 19 years or older who participated in the second (2011) and third (2012) years of the fifth wave of the KNHANES. ${ }^{16)}$ Of the 12,859 survey participants, we 
excluded 4,362 with data missing for MetS components (1,659 participants) or microalbuminuria (892 participants). We also excluded participants who fasted for less than 12 hours (1,705 participants) and those with macroalbuminuria ( $>300 \mathrm{mg} / \mathrm{g}, 106$ participants). Thus, a total of 8,497 subjects $(3,625 \mathrm{men}$ and 4,872 women) were included in the analysis. The study protocol was approved by the institutional review board of the Samsung Medical Center, Seoul, Korea (2014-06-026).

\section{Data Collection and Measurement of Metabolic Risk Factors}

The KNHANES is composed of three parts: a health interview, a health examination, and a nutrition survey. Data on medication use (antihypertensive agents and hypoglycemic agents) and health behaviors such as smoking, alcohol consumption, and level of physical activity were collected using a self-administered questionnaire. ${ }^{16}$ Based on the smoking status, subjects were categorized into three groups: never smokers, ex-smokers, and current smokers. Based on the alcohol consumption, subjects were categorized as nondrinkers, occasional drinkers (no more than once a week), and frequent drinkers (at least twice a week) ${ }^{17}$ ) We categorized subjects into a physically active group or inactive group based on the strength, duration, and frequency of their physical activity. The physically active group included those involved in a moderate level of physical activity for at least 30 minutes per day for 5 days per week or vigorous physical activity for at least 20 minutes per day for 3 days per week. ${ }^{18)}$

Data on education level were collected through the health interview and categorized into three groups according to the years of education achieved: $\leq 9$ years (middle school or lower level), 10 to 12 years (high school), and $\geq 13$ years (college or higher).

Body size measurements were conducted by trained medical staff according to standardized procedures. Height and weight were measured to the nearest $0.1 \mathrm{~cm}$ and $0.1 \mathrm{~kg}$, respectively. Body mass index (BMI) was calculated by dividing weight $(\mathrm{kg})$ by height squared $\left(\mathrm{m}^{2}\right)$. Waist circumference was measured at the midpoint between the lowest level of the ribs and the iliac crest at the mid-axillary line. Blood pressure (BP) was measured three times at 5-minute intervals using a sphygmomanometer with the individual in a sitting position. For our analysis, the mean value of the second and third measurements was used.

Blood samples were taken after fasting for at least 12 hours. The levels of glucose, triglyceride, and HDLC were measured using the Hitachi Automatic Analyzer 7600 (Hitachi, Tokyo, Japan) in a qualified central laboratory.

A random urine sample was collected during the first morning void, and urinary albumin concentration $(\mu \mathrm{g})$ was measured using a turbidimetric immunoassay (Hitachi Automatic Analyzer 7600). Urinary creatinine concentration (mg) was measured using a colorimetric method (Hitachi Automatic Analyzer 7600), and the albumin-to-creatinine ratio $(\mathrm{mg} / \mathrm{g})$ was calculated by dividing the urinary albumin concentration by the urinary creatinine concentration. Microalbuminuria was defined as a urinary albumin-to-creatinine ratio of 30 to $300 \mathrm{mg} / \mathrm{g}$, in accordance with the definition of the International Diabetes Federation. ${ }^{19)}$

\section{Definition of Metabolic Syndrome}

In the present study, we used a definition of MetS recommended by the joint interim statement of international organizations (International Diabetes Federation; National Heart, Lung, and Blood 
Institute; American Heart Association; World Heart Federation; International Atherosclerosis Society; and International Association for the Study of Obesity). ${ }^{1)}$

MetS was defined by the presence of three or more of the following risk factors: abdominal obesity (waist circumference $\geq 90 \mathrm{~cm}$ for men and $\geq 80 \mathrm{~cm}$ for women), high BP (systolic BP $\geq 130 \mathrm{~mm} \mathrm{Hg}$ and/or diastolic $\mathrm{BP} \geq 85 \mathrm{~mm} \mathrm{Hg}$ ), hypertriglyceridemia ( $\geq 150 \mathrm{mg} / \mathrm{dL}$ ), low HDLC level ( $<40 \mathrm{mg} / \mathrm{dL}$ for men and $<50 \mathrm{mg}$ ) $\mathrm{dL}$ for women), or high fasting glucose level $(\geq 100 \mathrm{mg} / \mathrm{dL})$. Subjects who reported taking antihypertensive agents or hypoglycemic agents were considered to have high BP or a high fasting glucose level, respectively.

\section{Statistical Analysis}

We compared the characteristics of study subjects according to the presence of MetS using the $\chi^{2}$ test for categorical variables and t-test for continuous variables. We evaluated the association between MetS and microalbuminuria using logistic regression analysis. For multivariable-adjusted analysis, age, smoking status, alcohol consumption, physical inactivity, and education level were defined as covariates.

All analyses were conducted using IBM SPSS ver. 21.0 for Windows (IBM Co., Armonk, NY, USA) taking sampling weights and the complex survey design into consideration. We considered a two-tailed P-value $<0.05$ to be statistically significant.

\section{RESULTS}

The weighted MetS prevalence in the present study was $28.8 \%$ for women and $26.3 \%$ for men, and the weighted prevalence of microalbuminuria was $6.7 \%$ for women and $5.2 \%$ for men. Figure 1 shows the prevalence of microalbuminuria according to MetS status. In men, $11 \%$ of those with MetS had microalbuminuria, whereas only $3.1 \%$ of those without MetS had microalbuminuria $(\mathrm{P}<0.001)$. In women, the prevalence of microalbuminuria was $14.4 \%$ in those with MetS and 6.7\% in those without MetS $(\mathrm{P}<0.001)$.

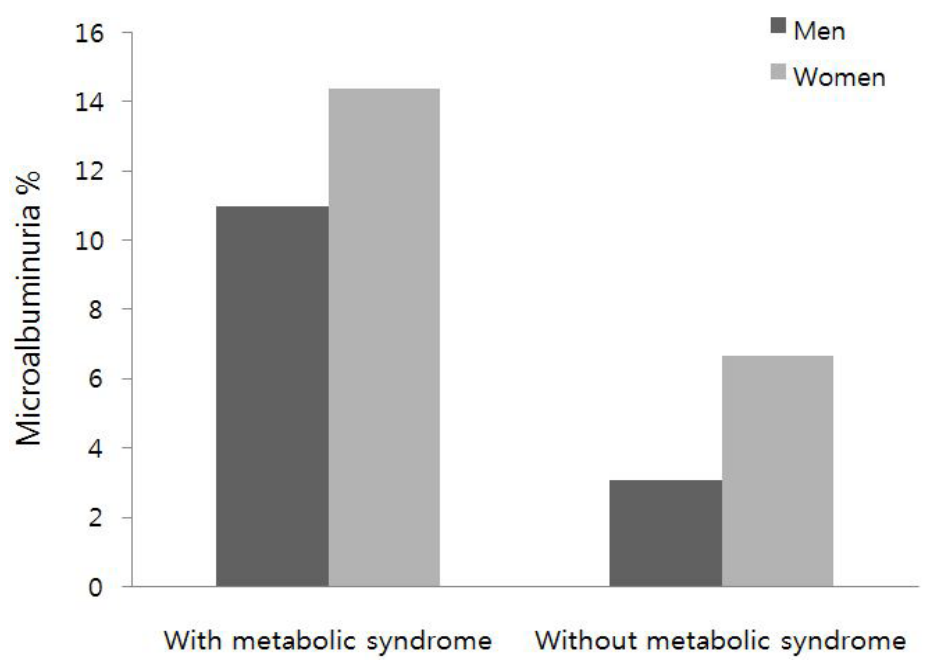

Figure 1. Prevalence of microalbuminuria according to metabolic syndrome. 
Table 1 shows the weighted demographic and clinical characteristics of study subjects. For both sexes, the albumin-to-creatinine ratio was significantly higher in subjects with MetS than in those without MetS. The waist circumference, BMI, systolic and diastolic BP, fasting glucose level, and triglyceride level were significantly higher, whereas HDLC level was significantly lower, in subjects with MetS than in those without MetS for both sexes. The distribution in terms of smoking status and physical inactivity did not differ between women with and without MetS, whereas current smoking and physical inactivity were more prevalent in men with MetS than in those without MetS. Although alcohol consumption was less prevalent in subjects with MetS for both sexes, frequent drinking was more prevalent in the MetS group in men, whereas occasional drinking was more prevalent in the MetS group in women. The level of education tended to be lower in subjects with MetS than in those without MetS for both sexes.

Table 1. Characteristics of study subjects according to MetS

\begin{tabular}{|c|c|c|c|c|c|c|}
\hline \multirow{2}{*}{ Characteristic } & \multicolumn{3}{|c|}{ Women } & \multicolumn{3}{|c|}{ Men } \\
\hline & With MetS & Without MetS & P-value ${ }^{*}$ & With MetS & Without MetS & P-value ${ }^{*}$ \\
\hline Number & 1,606 & 3,266 & & 1,058 & 2,567 & \\
\hline Age (y) & $59.2(0.5)$ & $43.2(0.4)$ & $<0.001$ & $50.4(0.7)$ & $43(0.8)$ & $<0.001$ \\
\hline Height $(\mathrm{cm})$ & $155.0(0.2)$ & $157.9(0.1)$ & $<0.001$ & $170.2(0.3)$ & $171.1(0.2)$ & 0.003 \\
\hline Waist circumference $(\mathrm{cm})$ & $86.9(0.3)$ & $75.1(0.2)$ & $<0.001$ & $91.7(0.4)$ & $81.6(0.26)$ & $<0.001$ \\
\hline Body mass index $\left(\mathrm{kg} / \mathrm{m}^{2}\right)$ & $26.0(0.1)$ & $22.5(0.01)$ & $<0.001$ & $26.4(0.2)$ & $23.3(0.1)$ & $<0.001$ \\
\hline $\begin{array}{l}\text { Systolic blood pressure } \\
(\mathrm{mm} \mathrm{Hg})\end{array}$ & $128.3(0.7)$ & $110.7(0.3)$ & $<0.001$ & $128.5(0.7)$ & $117.1(0.4)$ & $<0.001$ \\
\hline $\begin{array}{l}\text { Diastolic blood pressure } \\
\quad(\mathrm{mm} \mathrm{Hg})\end{array}$ & $77.7(0.4)$ & $71.6(0.2)$ & $<0.001$ & $84.2(0.5)$ & $76.8(0.3)$ & $<0.001$ \\
\hline Fasting glucose $(\mathrm{mg} / \mathrm{dL})$ & $108.3(0.9)$ & $89.7(0.2)$ & $<0.001$ & $110.3(1.0)$ & $93.6(0.4)$ & $<0.001$ \\
\hline Triglyceride (mg/dL) & $177.6(3.2)$ & $90.7(1.1)$ & $<0.001$ & $241.4(7.1)$ & $117.3(1.8)$ & $<0.001$ \\
\hline $\begin{array}{l}\text { High density lipoprotein } \\
\text { cholesterol (mg/dL) }\end{array}$ & $44.2(0.4)$ & $55.2(0.3)$ & $<0.001$ & $40.8(0.4)$ & $49.0(0.3)$ & $<0.001$ \\
\hline Smoking (\%) & & & 0.59 & & & $<0.001$ \\
\hline Never smoker & 89.7 & 89.3 & & 17.0 & 27.5 & \\
\hline Ex-smoker & 4.5 & 4.0 & & 38.0 & 29.5 & \\
\hline Current smoker & 5.8 & 6.7 & & 45.1 & 43.0 & \\
\hline Alcohol & & & $<0.001$ & & & $<0.001$ \\
\hline Nondrinker & 18.9 & 17.1 & & 9.7 & 9.3 & \\
\hline $\begin{array}{l}\text { Occasional drinker } \\
\text { ( } \leq \text { once/wk })\end{array}$ & 75.8 & 73.1 & & 45.2 & 55.5 & \\
\hline $\begin{array}{l}\text { Frequent drinker } \\
\text { ( } \geq \text { twice/wk) }\end{array}$ & 5.3 & 9.8 & & 45.1 & 35.2 & \\
\hline Physically inactive & 86.0 & 84.2 & 0.16 & 82.9 & 77.6 & 0.01 \\
\hline $\begin{array}{l}\text { Year of education } \\
\text { achieved (y) }\end{array}$ & & & $<0.001$ & & & $<0.001$ \\
\hline$\leq 9$ & 65.2 & 26.1 & & 31.5 & 19.0 & \\
\hline $10-12$ & 24.8 & 39.7 & & 37.9 & 44.1 & \\
\hline$\geq 13$ & 10.0 & 34.2 & & 30.6 & 36.9 & \\
\hline Medication use & & & & & & \\
\hline Antihypertensive agents & 45.1 & 7.2 & $<0.001$ & 31.8 & 7.7 & $<0.001$ \\
\hline Hypoglycemic agents & 16.2 & 1.0 & $<0.001$ & 13.5 & 2.9 & $<0.001$ \\
\hline Lipid-lowering agent & 13.4 & 3.1 & $<0.001$ & 8.5 & 2.5 & $<0.001$ \\
\hline $\begin{array}{l}\text { Albumin/creatinine ratio } \\
(\mathrm{mg} / \mathrm{g})\end{array}$ & $18.1(1.2)$ & $6.9(0.4)$ & $<0.001$ & $14.7(1.3)$ & $6.1(0.4)$ & $<0.001$ \\
\hline
\end{tabular}

Values are presented as mean (standard error) or percentage.

MetS: metabolic syndrome.

${ }^{*} \mathrm{P}$-values were obtained by t-test or $\chi^{2}$ test. 
Table 2 shows the association between MetS and its components with microalbuminuria for women. Compared with those without MetS, women with MetS had a 2.79-fold higher risk of microalbuminuria after adjusting for covariates. Analysis of the association between each MetS component and microalbuminuria indicated that all components were associated with a significantly increased risk of microalbuminuria after adjusting for covariates, with the strongest association occurring for high BP (odds ratio [OR], 2.99; 95\% confidence interval [CI], 2.08 to 4.28) and the lowest association for HDLC level (OR, 1.51; 95\% CI, 1.12 to 2.05 ). When we repeated the analyses after applying the criterion for abdominal obesity of waist circumference $\geq 85 \mathrm{~cm}$, as recommended by the Korean Society for the Study of Obesity, ${ }^{16}$ the association between MetS or abdominal obesity and microalbuminuria did not change (data not shown).

Table 2. Association of MetS and its components with microalbuminuria in women

\begin{tabular}{|c|c|c|c|c|c|}
\hline \multirow{2}{*}{ Component } & \multicolumn{2}{|c|}{ Microalbuminuria (\%) } & \multirow{2}{*}{ P-value } & \multirow{2}{*}{$\begin{array}{c}\text { Unadjusted }^{*} \\
\text { OR }(95 \% \mathrm{CI})\end{array}$} & \multirow{2}{*}{$\frac{\text { Multivariable-adjusted }^{\dagger}}{\text { OR }(95 \% \mathrm{CI})}$} \\
\hline & Yes $(n=366)$ & No $(n=4,506)$ & & & \\
\hline \multicolumn{6}{|c|}{ Waist circumference $\geq 80 \mathrm{~cm}$} \\
\hline No & 3.8 & 96.2 & $<0.001$ & 1 & 1 \\
\hline Yes & 10.8 & 89.2 & & $3.10(2.33-4.12)$ & $2.16(1.60-2.91)$ \\
\hline \multicolumn{6}{|c|}{$\begin{array}{c}\text { Blood pressure } \geq 130 / 85 \mathrm{~mm} \mathrm{Hg} \\
\text { or antihypertensive agent use }\end{array}$} \\
\hline No & 3.2 & 96.8 & $<0.001$ & 1 & 1 \\
\hline Yes & 14.1 & 85.9 & & $4.99(3.65-6.83)$ & $2.99(2.08-4.28)$ \\
\hline \multicolumn{6}{|c|}{ Triglyceride level $\geq 150 \mathrm{mg} / \mathrm{dL}$} \\
\hline No & 5.4 & 94.6 & $<0.001$ & 1 & 1 \\
\hline Yes & 11.3 & 88.7 & & $2.22(1.70-2.90)$ & $1.55(1.16-2.07)$ \\
\hline \multicolumn{6}{|c|}{$\begin{array}{l}\text { High-density lipoprotein } \\
\text { cholesterol level }<50 \mathrm{mg} / \mathrm{dL}\end{array}$} \\
\hline No & 4.7 & 95.3 & $<0.001$ & 1 & 1 \\
\hline Yes & 9.0 & 91.0 & & $2.02(1.54-2.65)$ & $1.51(1.12-2.05)$ \\
\hline \multicolumn{6}{|c|}{$\begin{array}{l}\text { Fasting glucose } \geq 100 \mathrm{mg} / \mathrm{dL} \\
\text { or hypoglycemic agents use }\end{array}$} \\
\hline No & 4.6 & 95.4 & $<0.001$ & 1 & 1 \\
\hline Yes & 14.2 & 85.8 & & $3.46(2.63-4.55)$ & $2.26(1.70-3.01)$ \\
\hline \multicolumn{6}{|l|}{ MetS } \\
\hline No & 3.6 & 96.4 & $<0.001$ & 1 & 1 \\
\hline Yes & 14.4 & 85.6 & & $4.44(3.37-5.85)$ & $2.79(2.01-3.88)$ \\
\hline
\end{tabular}

OR: odds ratio, CI: confidence intervals, MetS: metabolic syndrome.

${ }^{*}$ ORs and $95 \%$ CIs were estimated using logistic regression analyses. ${ }^{\dagger}$ Multivariable-adjusted analysis was conducted with an adjustment for age, smoking status, alcohol consumption, physical inactivity, and education level. 
Table 3 shows the association between MetS and its components and microalbuminuria for men. Compared with those without MetS, men with MetS had 3-fold higher risk of microalbuminuria after adjusting for covariates. We also found an association between individual MetS components and microalbuminuria, with all of the MetS components associated with a significantly increased risk of microalbuminuria after adjusting for covariates, the strongest being high BP (OR, 3.33; 95\% CI, 2.20 to 5.05 ) and the weakest being HDLC (OR, 1.56; 95\% CI, 1.11 to 2.19).

Table 3. Association of MetS and its components with microalbuminuria in men

\begin{tabular}{|c|c|c|c|c|c|}
\hline \multirow{2}{*}{ Component } & \multicolumn{2}{|c|}{ Microalbuminuria (\%) } & \multirow{2}{*}{ P-value } & \multirow{2}{*}{$\begin{array}{c}\text { Unadjusted }^{*} \\
\text { OR }(95 \% \mathrm{CI})\end{array}$} & \multirow{2}{*}{$\frac{\text { Multivariable-adjusted }^{\dagger}}{\text { OR }(95 \% \mathrm{CI})}$} \\
\hline & Yes $(n=366)$ & No $(n=4,506)$ & & & \\
\hline \multicolumn{6}{|c|}{ Waist circumference $\geq 90 \mathrm{~cm}$} \\
\hline No & 4.0 & 96.0 & $<0.001$ & 1 & 1 \\
\hline Yes & 8.8 & 91.2 & & $2.34(1.66-3.31)$ & $2.22(1.55-3.18)$ \\
\hline \multicolumn{6}{|c|}{$\begin{array}{l}\text { Blood pressure } \geq 130 / 85 \mathrm{~mm} \mathrm{Hg} \\
\text { or antihypertensive agent use }\end{array}$} \\
\hline No & 2.2 & 97.8 & $<0.001$ & 1 & 1 \\
\hline Yes & 9.4 & 90.6 & & $4.65(3.13-6.91)$ & $3.33(2.20-5.05)$ \\
\hline \multicolumn{6}{|c|}{ Triglyceride level $\geq 150 \mathrm{mg} / \mathrm{dL}$} \\
\hline No & 3.9 & 96.1 & $<0.001$ & 1 & 1 \\
\hline Yes & 7.7 & 92.3 & & $2.07(1.52-2.83)$ & $2.03(1.49-2.75)$ \\
\hline \multicolumn{6}{|c|}{$\begin{array}{l}\text { High density lipoprotein } \\
\text { cholesterol level }<40 \mathrm{mg} / \mathrm{dL}\end{array}$} \\
\hline No & 4.4 & 95.6 & $<0.001$ & 1 & 1 \\
\hline Yes & 7.4 & 92.6 & & $1.71(1.22-2.41)$ & $1.56(1.11-2.19)$ \\
\hline \multicolumn{6}{|c|}{$\begin{array}{l}\text { Fasting glucose } \geq 100 \mathrm{mg} / \mathrm{dL} \\
\text { or hypoglycemic agents use }\end{array}$} \\
\hline No & 3.4 & 96.6 & $<0.001$ & 1 & 1 \\
\hline Yes & 9.4 & 90.6 & & $2.90(2.09-4.03)$ & $1.98(1.43-2.75)$ \\
\hline \multicolumn{6}{|l|}{ MetS } \\
\hline No & 3.1 & 96.9 & $<0.001$ & 1 & 1 \\
\hline Yes & 11.0 & 89.0 & & $3.83(2.74-5.36)$ & $3.00(2.11-4.27)$ \\
\hline
\end{tabular}

OR: odds ratio, CI: confidence intervals, MetS: metabolic syndrome.

*ORs and 95\% CIs were estimated using logistic regression analyses. ${ }^{\star}$ Multivariable-adjusted analysis was conducted with an adjustment for age, smoking status, alcohol consumption, physical inactivity, and education level.

Figure 2 shows that, for both sexes, the risk of microalbuminuria gradually increased in a dosedependent manner with each increase in the number of MetS components ( $\mathrm{P}$ for trend $<0.001$ ). Compared with those without any MetS component, those with five of the MetS components had a 7.97-fold (95\% CI, 4.20 to 15.11) higher risk of microalbuminuria for women, and a 10.43 -fold ( $95 \%$ CI, 3.81 to 28.53) higher risk of microalbuminuria for men, respectively, after adjusting for covariates. 


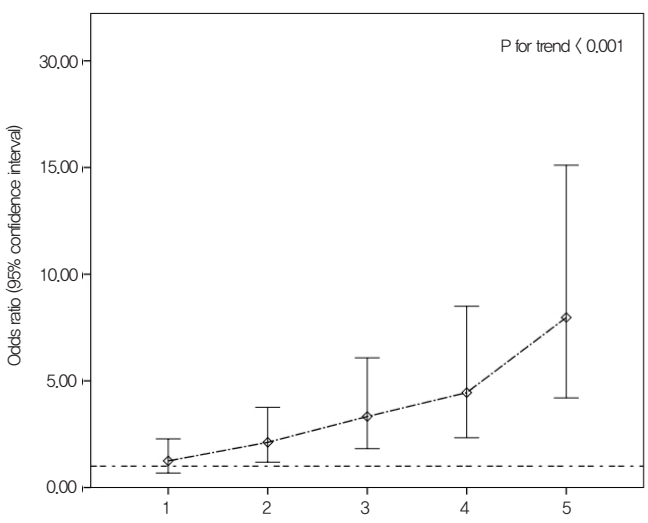

A

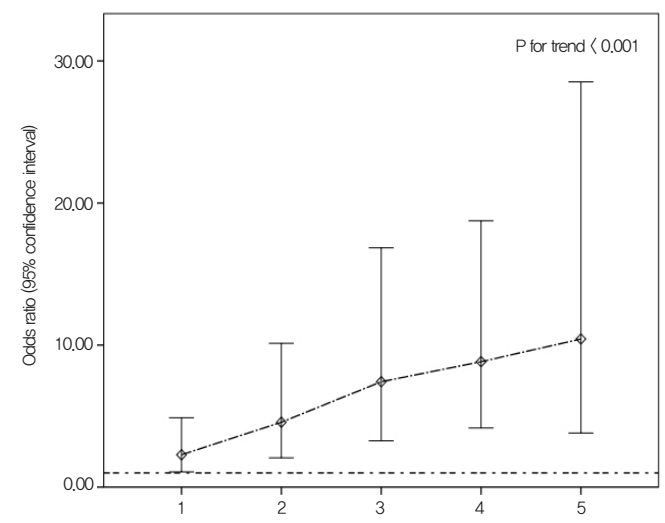

B

Figure 2. Association between the number of metabolic syndrome components and microalbuminuria. Multivariableadjusted analysis was conducted with an adjustment for age, smoking status, alcohol consumption, physical inactivity, and education level. (A) Women. (B) Men.

\section{DISCUSSION}

In this large population-based cross-sectional study of Korean adults, we found that MetS and each component of MetS were positively associated with microalbuminuria for both sexes, even after adjusting for covariates. The risk of microalbuminuria tended to increase as the number of MetS components increased.

Previous studies have consistently shown a positive association between MetS and CKD, as assessed by estimated GFR, regardless of the various definitions of MetS applied in these studies. ${ }^{6,8)}$ In addition, this association has been found consistently in studies of subjects without diabetes ${ }^{(6)}$ as well as in studies of diabetic patients. ${ }^{20,21)}$

Although few studies have evaluated the relationship between MetS and microalbuminuria, ${ }^{12-15,22)}$ most have found a significant association. In a community study of Japanese people aged 40 to 87 years, MetS was associated with an increased risk of microalbuminuria with an OR (95\% CI) of 1.99 (1.49 to 2.66) after adjusting for age and sex. ${ }^{13)}$ A Korean study also found a significant association between MetS and microalbuminuria, although that study was conducted on relatively healthy subjects with a much lower MetS prevalence (10.4\%) than the general Korean population. ${ }^{12)}$ The consistency in findings between these studies, including our study, suggest that the observed association between MetS and microalbuminuria is true. However, given that most studies on this issue have been conducted with a cross-sectional design, prospective studies would be needed to confirm the positive association between MetS and microalbuminuria.

Despite the consistent association between MetS and microalbuminuria in previous studies, findings on the association between individual MetS components and microalbuminuria were controversial. 
Fasting glucose level and BP were consistently found to be associated with microalbuminuria; however, differing results were reported for the association between microalbuminuria and abdominal obesity and HDLC and triglyceride levels. ${ }^{12,13,15)}$ The previously cited Japanese study showed that high glucose level and high BP were the main components of MetS associated with an increased risk of microalbuminuria, whereas they showed no association for the other components. ${ }^{13)}$ In the Japanese study, abdominal obesity was defined as a BMI $\geq 25 \mathrm{~kg} / \mathrm{m}^{2}$ as opposed to a measure based on waist circumference, and thus, the findings on abdominal obesity from that study cannot be compared directly with those from other studies using data based on waist circumference. In another study using data from the National Health and Nutrition Examination Survey III in the United States, ${ }^{15)}$ high BP and high glucose level were associated with microalbuminuria for both sexes, whereas low HDLC and high triglyceride levels were not. Finally, the previous Korean study ${ }^{12)}$ found a significant association between microalbuminuria and all MetS components with the exception of waist circumference.

Our study is the first to show a significant association between microalbuminuria and all components of MetS, although fasting glucose level and BP had higher ORs than other components. The underlying biological mechanism for the association between high BP and microalbuminuria may be related to the renal hemodynamic changes associated with essential hypertension: direct transmission of increased systemic pressure to the glomeruli, increased glomerular filtration, reduced tubular reabsorption of albumin, and structural damage to the glomeruli and arterioles. ${ }^{23,24)}$ The mechanisms involved in the association between elevated fasting glucose level and microalbuminuria may be similar to those involved in the development of microalbuminuria in type-2 diabetes: damage of the glomerular filtration barrier, reactive oxygen species, inflammatory cytokines, and growth factors. ${ }^{25)}$ Although the mechanisms of the association between lipid levels and progression of renal disease are not yet fully understood, abnormal serum lipoprotein levels in addition to diabetes and hypertension could precede, and possibly be responsible for, the development of atherosclerosis and nephrosclerosis resulting in microalbuminuria. ${ }^{26}$ ) In an animal model, lipid-lowering agents were found to improve glomerular damage, preventing glomerulosclerosis and interstitial fibrosis. ${ }^{27)}$ In addition, the similarities of anatomical origin and functional properties between glomerular mesangial cells and vascular smooth muscle cells seemed to provide clues to analogous cellular responses common to both atherosclerosis and glomerulosclerosis. ${ }^{26,28)}$

In this study, we used the albumin-to-creatinine ratio as a measure of microalbuminuria. Traditionally, albumin excretion rate has been measured on the basis of a 24-hour urine collection. However, 24-hour urine collection has some disadvantages such as inconvenience and a low reliability related to collection errors. Recently, critics have raised the issue that there has been no evidence that timed urine collection provides more clinically valid information than a urinary albumin-to-creatinine ratio, ${ }^{29)}$ and studies have revealed that spot urinary albumin-to-creatinine ratio for the detection of albuminuria gives similar values to those obtained from 24-hour urine collection. ${ }^{30)}$ Thus, in accordance with recommendations published by major international organizations, including the National Kidney Foundation, the American Diabetes Association, the International Diabetes Federation, and the National Institutes of Health, most recent studies have used the albumin-to-creatinine ratio from a spot urine sample to detect microalbuminuria. ${ }^{29}$ 
The present study has a number of strengths. First, study subjects were selected from the participants of the KNHANES, a highly comprehensive nationwide survey, which supports the generalizability of our results. Second, we were able to consider a wide range of covariates, which allowed a more accurate evaluation of the association between MetS and microalbuminuria.

However, the present study also has some limitations. First, its cross-sectional design made it difficult to infer causality between MetS and microalbuminuria. However, in a biological sense, it seems less plausible that microalbuminuria resulted in MetS. Second, microalbuminuria was assessed only once, which could have resulted in some misclassifications of microalbuminuria. Third, we did not consider subjects receiving lipid-lowering therapy to have high triglyceride or low HDLC levels, because we could not ascertain the exact purpose of this medication given the clinical situation that lipid-lowering agents can be prescribed to decrease low-density lipoprotein cholesterol or triglyceride levels or to increase HDLC levels. However, when we repeated the analyses after recategorizing those taking lipid-lowering agents into those with high triglyceride levels and those with low HDLC levels, the association between MetS and microalbuminuria did not change. Fourth, we could not consider the amount of alcohol consumption and more detailed information about physical activity. Finally, a large number of KNHANES participants were excluded from this study due to missing or inaccurate information on metabolic components. This may have reduced the representativeness of our study.

In conclusion, this study showed that MetS is significantly associated with microalbuminuria in the Korean population, and this association increases in a dose-dependent manner with the number of MetS components. These findings suggest that MetS is a risk factor for CKD from an early stage.

\section{CONFLICT OF INTEREST}

No potential conflict of interest relevant to this article was reported.

\section{ACKNOWLEDGMENTS}

This research was supported by Basic Science Research Program through the National Research Foundation of Korea funded by the Ministry of Science, ICT and future Planning (2014R1A2A2A01002705).

\section{REFERENCES}

1. Alberti KG, Eckel RH, Grundy SM, Zimmet PZ, Cleeman JI, Donato KA, et al. Harmonizing the metabolic syndrome: a joint interim statement of the International Diabetes Federation Task Force on Epidemiology and 
Prevention; National Heart, Lung, and Blood Institute; American Heart Association; World Heart Federation; International Atherosclerosis Society; and International Association for the Study of Obesity. Circulation 2009;120:1640-5.

2. Mozumdar A, Liguori G. Persistent increase of prevalence of metabolic syndrome among U.S. adults: NHANES III to NHANES 1999-2006. Diabetes Care 2011;34:216-9.

3. Lim S, Shin H, Song JH, Kwak SH, Kang SM, Won Yoon J, et al. Increasing prevalence of metabolic syndrome in Korea: the Korean National Health and Nutrition Examination Survey for 1998-2007. Diabetes Care 2011;34:1323-8.

4.Galassi A, Reynolds K, He J. Metabolic syndrome and risk of cardiovascular disease: a meta-analysis. Am J Med 2006;119:812-9.

5. Lakka HM, Laaksonen DE, Lakka TA, Niskanen LK, Kumpusalo E, Tuomilehto J, et al. The metabolic syndrome and total and cardiovascular disease mortality in middle-aged men. JAMA 2002;288:2709-16.

6. Kurella M, Lo JC, Chertow GM. Metabolic syndrome and the risk for chronic kidney disease among nondiabetic adults. J Am Soc Nephrol 2005;16:2134-40.

7. Sun F, Tao Q, Zhan S. Metabolic syndrome and the development of chronic kidney disease among 118924 non-diabetic Taiwanese in a retrospective cohort. Nephrology (Carlton) 2010;15:84-92.

8. Lucove J, Vupputuri S, Heiss G, North K, Russell M. Metabolic syndrome and the development of CKD in American Indians: the Strong Heart Study. Am J Kidney Dis 2008;51:21-8.

9. Thomas G, Sehgal AR, Kashyap SR, Srinivas TR, Kirwan JP, Navaneethan SD. Metabolic syndrome and kidney disease: a systematic review and meta-analysis. Clin J Am Soc Nephrol 2011;6:2364-73.

10. Jin DC. Current status of dialysis therapy for ESRD patients in Korea. J Korean Med Assoc 2013;56:562-8.

11. Toto RD. Microalbuminuria: definition, detection, and clinical significance. J Clin Hypertens (Greenwich) 2004;6(11 Suppl 3):2-7.

12. Choi HS, Ryu SH, Lee KB. The relationship of microalbuminuria with metabolic syndrome. Nephron Clin Pract 2006;104:c85-93.

13. Hao Z, Konta T, Takasaki S, Abiko H, Ishikawa M, Takahashi $T$, et al. The association between microalbuminuria and metabolic syndrome in the general population in Japan: the Takahata study. Intern Med 2007;46:341-6.

14. Klausen KP, Parving HH, Scharling H, Jensen JS. The association between metabolic syndrome, microalbuminuria and impaired renal function in the general population: impact on cardiovascular disease and mortality. J Intern Med 2007;262:470-8.

15. Palaniappan L, Carnethon M, Fortmann SP. Association between microalbuminuria and the metabolic syndrome: NHANES III. Am J Hypertens 2003;16(11 Pt 1):952-8.

16. Ministry of Health and Welfare. The fifth Korea National Health and Nutrition Examination Survey (KNHANES V-1, V-2) [Internet]. Cheongju: Korea Centers for Disease Control and Prevention [cited 2014 Jan 3]. Available from: http://knhanes.cdc.go.kr/knhanes/index.do.

17. Kang HT, Linton JA, Shim JY. Serum ferritin level is associated with the prevalence of metabolic syndrome in Korean adults: the 2007-2008 Korean National Health and Nutrition Examination Survey. Clin Chim Acta 
2012;413:636-41.

18. Han MA, Kim KS, Park J, Kang MG, Ryu SY. Association between levels of physical activity and poor self-rated health in Korean adults: the third Korea National Health and Nutrition Examination Survey (KNHANES), 2005. Public Health 2009;123:665-9.

19. International Diabetes Federation. The IDF consensus worldwide definition of the metabolic syndrome [Internet]. Brussels: International Diabetes Federation [cited 2014 Aug 6]. Available from: http://www.idf. org/webdata/docs/MetSyndrome_FINAL.pdf.

20. Kitiyakara C, Yamwong S, Cheepudomwit S, Domrongkitchaiporn S, Unkurapinun N, Pakpeankitvatana $\mathrm{V}$, et al. The metabolic syndrome and chronic kidney disease in a Southeast Asian cohort. Kidney Int 2007;71:693-700.

21. Tozawa M, Iseki C, Tokashiki K, Chinen S, Kohagura K, Kinjo K, et al. Metabolic syndrome and risk of developing chronic kidney disease in Japanese adults. Hypertens Res 2007;30:937-43.

22. Chen J, Muntner P, Hamm LL, Jones DW, Batuman V, Fonseca V, et al. The metabolic syndrome and chronic kidney disease in U.S. adults. Ann Intern Med 2004;140:167-74.

23. Rodicio JL, Campo C, Ruilope LM. Microalbuminuria in essential hypertension. Kidney Int Suppl 1998;68:S51-4.

24. Hostetter TH, Olson JL, Rennke HG, Venkatachalam MA, Brenner BM. Hyperfiltration in remnant nephrons: a potentially adverse response to renal ablation. Am J Physiol 1981;241:F85-93.

25. Satchell SC, Tooke JE. What is the mechanism of microalbuminuria in diabetes: a role for the glomerular endothelium? Diabetologia 2008;51:714-25.

26. Diamond JR, Karnovsky MJ. Focal and segmental glomerulosclerosis: analogies to atherosclerosis. Kidney Int 1988;33:917-24.

27. Trevisan R, Dodesini AR, Lepore G. Lipids and renal disease. J Am Soc Nephrol 2006;17(4 Suppl 2):S145-7.

28. Klahr S, Schreiner G, Ichikawa I. The progression of renal disease. N Engl J Med 1988;318:1657-66.

29. Martin H. Laboratory measurement of urine albumin and urine total protein in screening for proteinuria in chronic kidney disease. Clin Biochem Rev 2011;32:97-102.

30. Zelmanovitz T, Gross JL, Oliveira JR, Paggi A, Tatsch M, Azevedo MJ. The receiver operating characteristics curve in the evaluation of a random urine specimen as a screening test for diabetic nephropathy. Diabetes Care 1997;20:516-9. 